\title{
Effect of Madden-Julian Oscillation Occurrence Frequency on the Interannual Variability of Northern Hemisphere Stratospheric Wave Activity in Winter
}

\author{
FEIYANG WANG AND Wenshou Tian \\ Key Laboratory for Semi-Arid Climate Change of the Ministry of Education, College of Atmospheric Science, \\ Lanzhou University, Lanzhou, China \\ FEI XIE \\ College of Global Change and Earth System Science, Beijing Normal University, Beijing, China \\ JIANKAI ZHANG AND YUANYUAN HAN \\ Key Laboratory for Semi-Arid Climate Change of the Ministry of Education, College of Atmospheric Science, \\ Lanzhou University, Lanzhou, China
}

(Manuscript received 17 July 2017, in final form 12 March 2018)

\begin{abstract}
This study uses reanalysis datasets and numerical experiments to investigate the influence of the occurrence frequency of the individual phases of the Madden-Julian oscillation (MJO) on the interannual variability of stratospheric wave activity in the middle and high latitudes of the Northern Hemisphere during boreal winter [November-February (NDJF)]. Our analysis reveals that the occurrence frequency of MJO phase 4 in winter is significantly positively correlated with the interannual variability of the Eliassen-Palm (E-P) flux divergence anomalies in the northern extratropical stratosphere; that is, higher (lower) occurrence frequency of MJO phase 4 corresponds to weaker (stronger) upward wave fluxes and increased (decreased) E-P flux divergence anomalies in the middle and upper stratosphere at mid-to-high latitudes, which implies depressed (enhanced) wave activity accompanied by a stronger (weaker) polar vortex in that region. The convection anomalies over the Maritime Continent related to MJO phase 4 excite a Rossby wave train that propagates poleward to middle and high latitudes, and is in antiphase with the climatological stationary waves of wavenumber 1 at middle and high latitudes. As the spatial distribution of the convection anomalies during MJO phase 7 has an almost opposite, but weaker, pattern to that during MJO phase 4, the occurrence frequency of MJO phase 7 has an opposite and weaker effect on the northern extratropical stratosphere to MJO phase 4. However, the other MJO phases $(1,2,3,5,6$, and 8) cannot significantly influence the northern extratropical stratosphere because the wave responses in these phases are neither totally in nor out of phase with the background stationary wavenumber 1.
\end{abstract}

\section{Introduction}

Planetary wave activity in the extratropical stratosphere plays an important role in the dynamical coupling between the troposphere and stratosphere (e.g., Kuroda and Kodera 1999; Perlwitz and Graf 2001; Kushner and Polvani 2004; Perlwitz and Harnik 2004). Previous studies have found that stratospheric wave activity has increased in the early winter but decreased significantly in the late

Corresponding author: Wenshou Tian,wstian@1zu.edu.cn winter during past decades (e.g., Newman and Nash 2000; Randel et al. 2002; Hu and Tung 2003). As wave activity in the extratropical stratosphere is a precursor to stratospheric events, the stratospheric polar vortex and Brewer-Dobson circulation (BDC) evolve with the wave activity (Polvani and Waugh 2004; Butchart et al. 2006; Garcia and Randel 2008; Garfinkel et al. 2015). The changing Arctic polar vortex and BDC can, in turn, influence the tropospheric weather and climate across a wide range of time scales (Thompson and Wallace 2001; Karpechko and Manzini 2012; Xie et al. 2016; Zhang et al. 2016). It is, therefore, important to understand the factors 
that control the variability of the wave activity in the northern extratropical stratosphere.

The stratospheric planetary wave activity shows pronounced interannual variability in winter in the Northern Hemisphere. It is well known that the interannual variability of the extratropical stratosphere is related to tropical variability, such as the quasi-biennial oscillation (QBO; Holton and Tan 1980, 1982; Garfinkel et al. 2012a; Lu et al. 2014) and El Niño-Southern Oscillation (ENSO; Calvo Fernández et al. 2004, 2009; Manzini et al. 2006; Camp and Tung 2007; Garfinkel and Hartmann 2008; Cagnazzo and Manzini 2009; Cagnazzo et al. 2009; Ren et al. 2012; Xie et al. 2012; Zhang et al. 2015a,b). Stratospheric planetary waves originate predominately in the troposphere, and their variations are caused by variability in two main factors: wave propagation from the troposphere into the stratosphere, and tropospheric wave activity intensity. Wave propagation from the troposphere into the stratosphere can be affected by the QBO. The QBO affects extratropical wave propagation in two ways: the first is the stratospheric waveguide change due to the modulation by the QBO of the latitudinal location of the zero-wind line (i.e., the critical line for stationary waves) in the subtropics (Holton and Tan 1980, 1982), and the other is changes to planetary wave propagation and breaking caused by the effect of the QBO-induced meridional circulation on the refractive index (e.g., Garfinkel et al. 2012a; Lu et al. 2014). Variations in the intensity of tropospheric wave activity are mainly driven by tropical processes, for example, by ENSO. Warm ENSO events induce a deepening of the winter Aleutian low via the Pacific-North American (PNA) pattern, leading to an increase in wavenumber- 1 eddies and a weakened vortex. However, the extratropical atmospheric circulation is not only influenced by ENSO and QBO, but also the Madden-Julian oscillation (MJO).

The MJO is the dominant mode of intraseasonal variability in the tropical atmosphere (Madden and Julian 1971, 1972, 1994). A typical MJO event begins with a convective disturbance over the far equatorial western Indian Ocean and then intensifies and propagates eastward slowly $\left(\sim 5 \mathrm{~m} \mathrm{~s}^{-1}\right)$ to the equatorial central Pacific Ocean. An MJO can be divided into eight phases as the convection center propagates. Previous studies have shown that these intraseasonal anomalies of moist deep convection in the tropics influence the teleconnection patterns over the middle and high latitudes, such as the PNA pattern (e.g., Matthews et al. 2004; Mori and Watanabe 2008; Johnson and Feldstein 2010), the North Atlantic Oscillation (NAO; e.g., Cassou 2008; Lin et al. 2009), and the Arctic Oscillation (AO; e.g., Zhou and Miller 2005; L'Heureux and Higgins 2008). Moreover, Lin et al. (2015) have also demonstrated that the seasonal mean convective activity related to MJO phases 3-5 is a possible driver of the seasonal mean NAO variability in boreal winter. According to the theoretical studies of Matsuno (1966) and Gill (1980), the coherence between tropical and extratropical responses triggered by MJO-related convection is a consequence of Rossby wave trains that extend eastward and poleward across the middle and high latitudes. A model-based study by Seo and Son (2012) suggested that the anomalous tropical heating related to MJO phase 3 results in a Rossby wave train traveling north from the tropics into the northern Pacific and North America, and then turning south toward the equatorial African continent. The spatial structure of such a Rossby wave train is similar to that of the PNA pattern. Furthermore, Yoo et al. $(2011,2012)$ showed that the surface air temperature in the Arctic is also linked to the tropical MJO through the poleward propagation of wave trains. In addition, the ozone transport between the upper troposphere and lower stratosphere over the northern extratropics and Arctic is also affected by the MJO-related teleconnection ( $\mathrm{Li}$ et al. 2013). The above studies illustrate that the MJO is able to influence wave activity in the northern extratropical troposphere. However, the connection between the MJO and wave activity in the northern extratropical stratosphere has received relatively little attention.

Newman and Sardeshmukh (2008) have shown a link between tropical diabatic heating on intraseasonal time scales and the polar vortex. Garfinkel et al. (2012b) found a clear correlation between wave activity in the extratropical stratosphere and the MJO. They suggested that Northern Hemisphere sudden stratospheric warming (SSW) events tend to follow certain MJO phases with a delay of a few days. Liu et al. (2014) investigated the connection between the equatorial MJO and different types of the Northern Hemisphere midwinter major SSWs. Subsequently, Garfinkel et al. (2014) pointed out more clearly that MJO phase 7 , in which convective anomalies propagate into the tropical central Pacific, leads to a North Pacific low, more heat flux in the troposphere, and a weakened vortex, whereas MJO phase 3 leads to the opposite effects. More recently, Schwartz and Garfinkel (2017) found that slightly more than half of SSW events follow MJO phases 6 and 7 . However, these studies focused solely on the relationship between these two processes over intraseasonal time scales. The question that arises here is the following: Can the MJO influence the interannual variability of Northern Hemisphere stratospheric wave activity? Even though the MJO operates over intraseasonal time scales, the occurrence frequency of the individual phases of the MJO actually shows year-to-year variability. The 





FIG. 1. Composite OLR $\left(\mathrm{W} \mathrm{m}^{-2}\right.$ ) anomalies during the eight MJO phases in boreal winter (NDJF). Daily OLR data for the period 1979-2013 were obtained from the CDC (NOAA) and the MJO phases were defined using the real-time multivariate MJO (RMM) index. Only days with MJO amplitude greater than 1.0 were used. OLR anomalies were calculated by removing the daily seasonal cycle and then applying a 100-day high-pass digital filter to the daily time series.

purpose of this paper is to investigate whether the interannual variability of the occurrence frequency of the individual phases of the MJO can significantly affect Northern Hemisphere stratospheric wave activity.

The remainder of this paper is organized as follows. Section 2 introduces the datasets, methods, and model. Section 3 demonstrates the statistical relationship between the interannual variability of the occurrence frequency of the individual phases of the MJO and wave activity in the northern extratropical stratosphere, and the associated mechanism is analyzed in section 4. Finally, we present our conclusions in section 5 .

\section{Data, methods, and model}

Interpolated $\left(2.5^{\circ}\right.$ longitude $\times 2.5^{\circ}$ latitude $)$ daily mean outgoing longwave radiation (OLR) data from 1979 to 2013 were obtained from the Climate Diagnostic Center (CDC) of the National Oceanic and Atmospheric Administration (NOAA). Note that the analysis in this study is limited to the period 1979-2013, corresponding to the availability of the OLR data. The OLR can serve as a proxy for deep convection in the tropics, with lower OLR values corresponding to enhanced convective activity. To identify MJO events, the daily multivariate MJO index (Wheeler and Hendon 2004), which characterizes the state of the MJO in terms of its amplitude and phase, was obtained from the Australian Bureau of Meteorology (online at http://www.bom.gov.au/climate/mjo/). This MJO index consists of the principal components of the leading combined empirical orthogonal functions (EOFs) of the 200- and 850-hPa zonal wind and OLR averaged over the latitude band between $15^{\circ} \mathrm{S}$ and $15^{\circ} \mathrm{N}$. Based on the index, an MJO cycle (typically $\sim 40$ 60 days) is divided into eight phases. The MJO is considered as being active when the amplitude of the MJO index exceeds 1.0. Figure 1 shows the composited OLR anomalies during the eight MJO phases. The original OLR MJO index (OOMI), which is obtained online from the NOAA/Earth System Research Laboratory (online at https://www.esrl.noaa.gov/psd/mjo/mjoindex/oomi.1x.txt), was also used to verify the results in this study.

The meteorological fields analyzed in this study were obtained from the National Centers for Environmental Prediction (NCEP)-National Center for Atmospheric Research(NCAR) reanalysis dataset (Kalnay et al. 1996). The dataset contains daily averages of variables on a $2.5^{\circ} \times 2.5^{\circ}$ grid at 17 vertical pressure levels extending from 1000 to $10 \mathrm{hPa}$, with 6 levels in the stratosphere $(100,70,50,30,20$, and $10 \mathrm{hPa})$. The reanalysis data from the European Centre for Medium-Range Weather Forecasts (ECMWF) interim reanalysis (ERAInterim; Dee et al. 2011) were also used to verify the results in this study, and were obtained as daily mean fields at 37 discrete pressure levels, on a $1^{\circ} \times 1^{\circ}$ horizontal grid. 
We used wave activity analysis to investigate the energy propagation of stationary Rossby waves. The wave activity flux is parallel to the group velocity of stationary Rossby waves, making it a useful indicator for identifying the propagation direction and source of stationary atmospheric Rossby waves. To assess the influence of MJO-related processes on wave activity in the extratropical stratosphere, the quasigeostrophic version of the E-P flux divergence was calculated using the NCEPNCAR daily fields based on the original definition as follows (Edmon et al. 1980):

$$
\nabla \cdot \mathbf{F}=\frac{1}{a \cos \varphi} \frac{\partial\left(F_{\varphi} \cos \varphi\right)}{\partial \varphi}+\frac{\partial F_{p}}{\partial p},
$$

where

$$
\begin{aligned}
& F_{\varphi}=-a(\cos \varphi) \overline{u^{\prime} v^{\prime}} \text { and } \\
& F_{p}=a(\cos \varphi) f \frac{\overline{v^{\prime} \theta^{\prime}}}{\theta_{p}} .
\end{aligned}
$$

Here $p$ is the pressure; $a$ is the radius of Earth; $\varphi$ is the latitude; $f$ is the Coriolis parameter; $\theta$ is the potential temperature; and $u$ and $v$ are the zonal and meridional components of the wind, respectively. Eddy flux terms are computed from the zonal anomalies for each day. The E-P fluxes include the wave momentum flux and wave heat flux. The E-P flux divergence reflects the eddy forcing on the zonal mean flow, which can serve as a measure of the wave activity, and a negative (positive) E-P flux divergence represents easterly (westerly) eddy forcing of the mean flow (Andrews et al. 1987).

Rossby wave ray tracing was used to further analyze the trajectory of the stationary Rossby wave train and characterize the impact of the background flow on the propagation of wave energy. This theory-based technique uses a curve that is locally tangential to the group velocity vector, and has been widely used to trace the Rossby wave responses to tropical heating anomalies (Hoskins and Karoly 1981; Hoskins and Ambrizzi 1993), and also in research into atmospheric teleconnection mechanisms (Xu et al. 2013; Sun et al. 2015, 2017; Wu et al. 2016; Zheng et al. 2016). The trajectory of a wave ray can be calculated numerically from the angle of the wave front propagation, which is determined from the ratio of the zonal and meridional group velocities. As the Rossby wave propagation trajectories are closely dependent on the basic state, the Rossby wave rays were calculated here for the seasonal climatological flow using the equations in $\mathrm{Li}$ and $\mathrm{Li}$ (2012), Li et al. (2015), and Zhao et al. (2015) to delineate the propagation behavior of wave energy associated with the MJO.
We used the NCAR Community Earth System Model (CESM), version 1.0.6, which is a global climate model (Hurrell et al. 2013). In particular, our model experiments were carried out using version 4 of the Whole Atmosphere Community Climate Model (WACCM4). WACCM4 also incorporates the Community Atmospheric Model, version 4 (CAM4), and as such includes all of its physical parameterizations (Neale et al. 2013). This improved version of WACCM uses a coupled system of four components: atmosphere, ocean, land, and sea ice (Holland et al. 2012). WACCM4 has a finitevolume dynamical core, with 66 vertical levels extending from the ground to $4.5 \times 10^{-6} \mathrm{hPa}(\sim 145-\mathrm{km}$ geometric altitude), and a vertical resolution of $1.1-1.4 \mathrm{~km}$ in the tropical tropopause layer and the lower stratosphere (below a height of $30 \mathrm{~km}$ ). The simulations presented in this paper are performed at a horizontal resolution of $1.9^{\circ} \times 2.5^{\circ}$, and include interactive chemistry (Garcia et al. 2007). More details about WACCM4 are available in Marsh et al. (2013).

In this study, all relevant daily data of 34-yr boreal winter [November-February (NDJF)] from 1979 to 2013 were analyzed. For all the fields except for the MJO index, the seasonal cycle was removed, and then a 100day high-pass digital filter was performed on the daily time series. Then, the seasonal means are constructed by averaging variables over NDJF, resulting in 34 winter fields. Note that an area average over the region $40^{\circ}-90^{\circ} \mathrm{N}$ and $10-100 \mathrm{hPa}$ was applied to the filtered E-P flux divergence for calculating the time series of wave activity in the extratropical stratosphere. The high-pass filter was chosen to retain atmospheric variations in intraseasonal time scale and exclude other factors (e.g., QBO or ENSO) that may contaminate the connection between MJO and wave activity in the extratropical stratosphere. After applying the high-pass filter to the E-P flux divergence time series, the standard deviation of the filtered seasonal mean time series was reduced, but the reduction was no more than half of the standard deviation of the unfiltered time series.

\section{The correlation between MJO occurrence frequency and wave activity in the northern extratropical stratosphere}

Figure 2 shows the time series of the occurrence frequency of the eight MJO phases, and the E-P flux divergence anomalies in the northern extratropical stratosphere, during winter (NDJF) from NCEP-NCAR reanalysis data. The occurrence frequency of the individual MJO phases was calculated by summing the occurrence days of each phase during winter in each year. Only the days with MJO amplitude greater than 

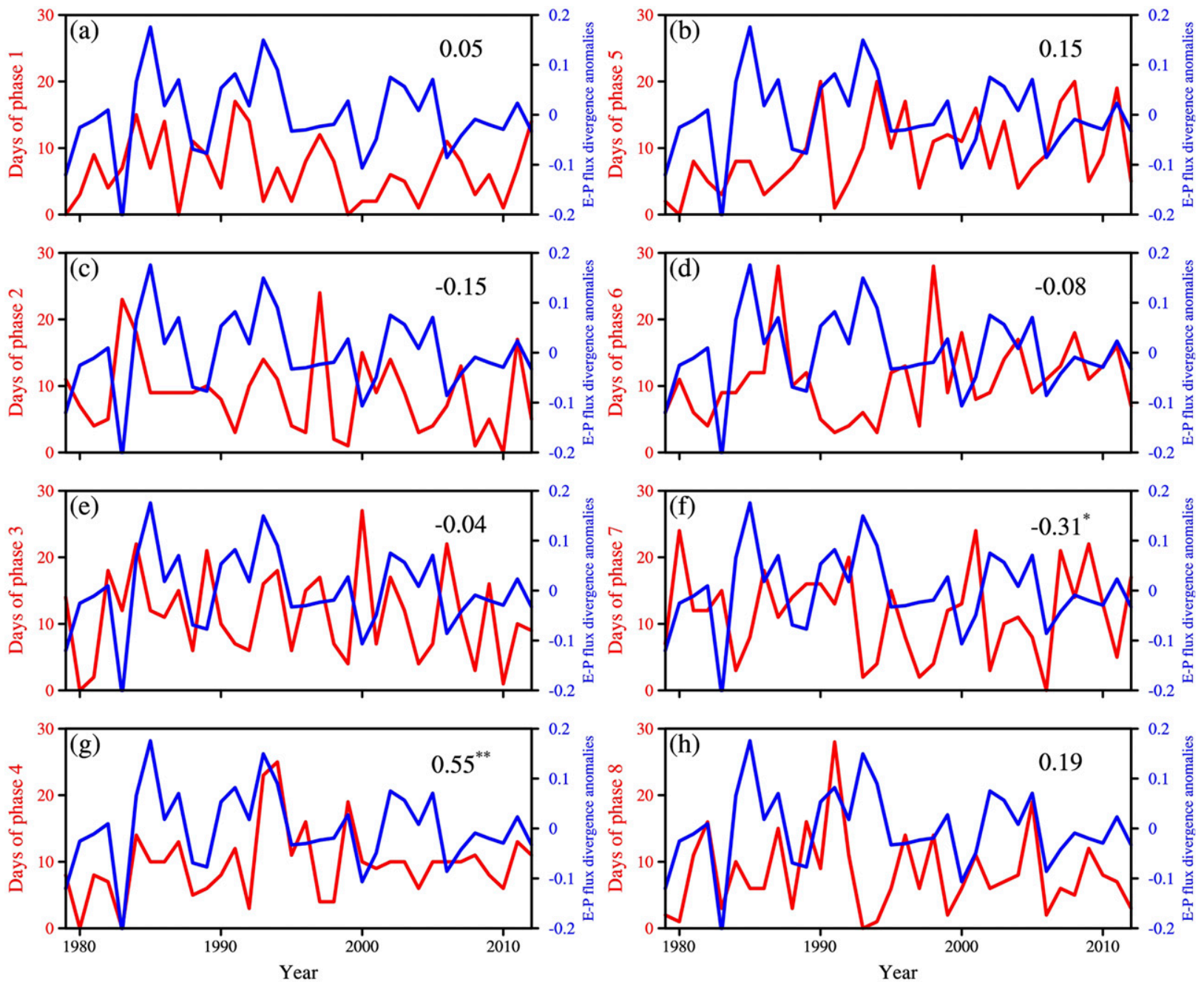

FIG. 2. Time series of the occurrence frequency of the eight MJO phases (day; red lines) and northern extratropical stratospheric E-P flux divergence anomalies ( $\mathrm{m} \mathrm{s}^{-1}$ day $^{-1}$; blue lines) during winter (NDJF) from 1979 to 2013 based on NCEP-NCAR reanalysis data. The occurrence frequency of the individual MJO phases was calculated by summing the occurrence days of each phase during winter in each year. Only days with MJO amplitude greater than 1.0 were included. The time series of E-P flux divergence anomalies was obtained by applying a spatial average over the region $40^{\circ}-90^{\circ} \mathrm{N}$ and $10-100 \mathrm{hPa}$ and a time average in winter, after removing the seasonal cycle and then applying a 100-day high-pass filter to the time series. The correlation coefficient between these two linearly detrended time series is shown in the top-right corner of each panel. One (two) asterisk(s) indicate that the correlation coefficient is significant at the $90 \%$ ( $95 \%$ ) confidence level based on the Student's $t$ test.

1.0 were included. A 100-day high-pass filter was applied to the E-P flux divergence anomalies before performing the spatial and time average. After the 100day high-pass filtering, the variations in the averaged E-P flux divergence anomalies highlight the interannual variations in the high-frequency northern extratropical stratospheric wave activity in winter. We found that strong in-phase variability exists between the occurrence frequency of MJO phase 4 and the northern extratropical stratospheric E-P flux divergence anomalies, with a correlation coefficient of 0.55 that is significant at the $95 \%$ confidence level
(Fig. 2g). Note that the occurrence frequency of MJO phase 7 has a relatively large anticorrelation with the E-P flux divergence anomalies $(R=-0.31$, significant at the $90 \%$ confidence level, Fig. 2f). These results suggest that an increase (decrease) in the occurrence frequency of MJO phase 4 during the boreal winter corresponds to weaker (stronger) wave activity in the northern extratropical stratosphere, and vice versa for MJO phase 7. Note that we also used different MJO amplitude threshold values (1.25 and 1.5) and different periods of high-pass filtering (120 and 80 days) to test the robustness of the link between the occurrence 
TABLE 1. The left column is the correlation coefficients between the frequency of occurrence of the individual MJO phases and E-P flux divergence anomalies in the extratropical stratosphere for an MJO amplitude threshold of 1.25 and 1.5 and the right column for filtering period of 120 and 80 days. When calculating the correlation coefficients for the MJO amplitude threshold of 1.25 and 1.5, the 100-day high-pass filtering is used. When calculating the correlation coefficients for filtering period of 120 and 80 days, the MJO amplitude threshold value 1.0 is used. The E-P flux divergence is calculated from the NCEP-NCAR reanalysis data. One and two asterisks indicate that the correlation coefficient is significant at the $90 \%$ and $95 \%$ confidence levels, respectively, based on the Student's $t$ test.

\begin{tabular}{|c|c|c|c|c|}
\hline & \multicolumn{2}{|c|}{ MJO amplitude threshold } & \multicolumn{2}{|c|}{ Filtering period } \\
\hline & 1.25 & 1.5 & 120 days & 80 days \\
\hline \multirow{8}{*}{$R$} & 0.11 & 0.24 & -0.01 & 0.07 \\
\hline & -0.02 & 0.19 & -0.15 & -0.19 \\
\hline & 0.01 & 0.07 & -0.06 & -0.03 \\
\hline & $0.56 * *$ & $0.47 * *$ & $0.55^{* *}$ & $0.53 * *$ \\
\hline & 0.13 & 0.18 & 0.13 & 0.19 \\
\hline & -0.05 & -0.04 & -0.09 & -0.02 \\
\hline & $-0.32 *$ & $-0.33^{*}$ & $-0.35^{*}$ & $-0.31 *$ \\
\hline & 0.25 & 0.18 & 0.17 & 0.2 \\
\hline
\end{tabular}

frequency of MJO phases and the northern stratospheric wave activity found in our study. Table 1 lists the correlation coefficients between the frequency of occurrence of the individual MJO phase and E-P flux divergence anomalies under the choice of different MJO amplitude threshold values and different periods of high-pass filtering. It is apparent that the results are not sensitive to the selections of the MJO amplitude threshold value and the reasonable change in the period of the filtering. The corresponding results from the ERA-Interim data are well consistent with the correlations between the occurrence frequencies of MJO phases 4 and 7 and the northern extratropical stratospheric wave activity anomalies (Table 2).

In addition, previous studies have suggested that some factors, such as QBO, ENSO, North Pacific SST, subpolar snow cover, or sea ice, can affect northern extratropical stratospheric wave activity (e.g., Cohen and Jones 2011; Garfinkel et al. 2012a; Hurwitz et al. 2012; Kim et al. 2014; Chen et al. 2016). The link between the occurrence frequency of MJO phases and highfrequency variability of stratospheric wave activity may be affected by these factors. However, the 100-day highpass filter performed on the time series in this study eliminate the effects of the signals with time scales longer than 100 days. Meanwhile, we found that this link between the occurrence frequency of MJO phases and variability of wave activity in the northern stratosphere is stable when a multiple linear regression was further applied to remove the effects of the abovementioned
TABLE 2. As in Table 1, but for E-P flux divergence from ERA-Interim data.

\begin{tabular}{ccccccccc}
\hline \hline & \multicolumn{3}{c}{ MJO amplitude threshold } & & \multicolumn{3}{c}{ Filtering period } \\
\cline { 2 - 3 } \cline { 6 - 8 } & 1.0 & 1.25 & 1.5 & & 120 days & 100 days & 80 days \\
\hline$R$ & 0.12 & 0.15 & 0.25 & & 0.07 & 0.12 & 0.17 \\
& -0.13 & -0.02 & 0.13 & & -0.14 & -0.13 & -0.05 \\
-0.11 & 0.06 & 0.01 & & -0.14 & -0.11 & -0.08 \\
$0.45^{* *}$ & $0.46^{* *}$ & $0.36^{* *}$ & & $0.46^{* *}$ & $0.45^{* *}$ & $0.42^{* *}$ \\
0.10 & 0.08 & 0.12 & & 0.09 & 0.10 & 0.09 \\
-0.18 & -0.13 & -0.11 & & -0.21 & -0.18 & -0.2 \\
$-0.29^{*}$ & $-0.31^{*}$ & $-0.29 *$ & & $-0.32^{*}$ & $-0.29^{*}$ & $-0.29 *$ \\
0.17 & 0.21 & 0.13 & & 0.15 & 0.17 & 0.13 \\
\hline
\end{tabular}

factors on the filtered wave activity of the extratropical stratosphere (not shown).

Figure 1 shows that the tropical convection is strengthened over the Maritime Continent but suppressed over the central Pacific during MJO phase 4. In contrast, the pattern of convection anomalies during MJO phase 7 is approximately opposite to that associated with $\mathrm{MJO}$ phase 4. This explains why the occurrence frequencies of MJO phases 4 and 7 are oppositely correlated with the northern extratropical stratospheric wave activity anomalies (Figs. 2g,f). Using the data plotted in Fig. 1, the OLR anomalies spatially averaged over the Maritime Continent $\left(15^{\circ} \mathrm{S}-5^{\circ} \mathrm{N}, 90^{\circ}-150^{\circ} \mathrm{E}\right)$ and equatorial central Pacific $\left(15^{\circ} \mathrm{S}-5^{\circ} \mathrm{N}, 160^{\circ} \mathrm{E}-150^{\circ} \mathrm{W}\right)$ during the eight MJO phases are shown in Fig. 3; the convection anomalies at the center of the OLR anomalies during MJO phase 4 are more intense than those that develop during MJO phase 7. Under these circumstances, we can expect that the correlation coefficient between the occurrence frequency of MJO phase 4 and the E-P flux divergence anomalies (Fig. $2 \mathrm{~g}$ ) is more significant than that between $\mathrm{MJO}$ phase 7 and the E-P flux divergence anomalies (Fig. 2f). Note that the intensities of convection anomalies at the center of the OLR anomalies



FIG. 3. Composite OLR $\left(\mathrm{W} \mathrm{m}^{-2}\right)$ anomalies spatially averaged over the Maritime Continent $\left(15^{\circ} \mathrm{S}-5^{\circ} \mathrm{N}, 90^{\circ}-150^{\circ} \mathrm{E}\right)$ and equatorial central Pacific $\left(15^{\circ} \mathrm{S}-5^{\circ} \mathrm{N}, 160^{\circ} \mathrm{E}-150^{\circ} \mathrm{W}\right)$ during the eight $\mathrm{MJO}$ phases in winter (NDJF). Only days when the MJO amplitude was greater than 1.0 were used. OLR anomalies were calculated by removing the seasonal cycle and then applying a 100-day high-pass digital filter to the daily time series. 
during MJO phases 5 and 8 are also as large as those during MJO phases 4 and 7, respectively. The difference between the influences of the other MJO phases and these two special phases on wave activity will be discussed in the next section.

Garfinkel et al. (2014) showed that the enhanced convection in the tropical central Pacific associated with MJO phase 7 leads to a weakened Arctic polar vortex. Our study shows a similar result, with the increased occurrence frequency of MJO phase 7 corresponding to stronger wave activity in the northern extratropical stratosphere. They also showed that the weakened wave activity corresponds to suppressed convection in the central Pacific related to MJO phase 3; however, we have shown that the increased occurrence frequency of MJO phase 4 is related to weaker wave activity in the extratropical stratosphere. These differences may be caused by the different time scales considered by these two studies. Garfinkel et al. (2014) focused on the effect of one MJO phase on extratropical circulation with an intraseasonal time scale, whereas this study investigates the variability on interannual time scales of the link between the occurrence frequency of MJO phase and the northern stratospheric wave activity. The correlation coefficients between the E-P flux divergence anomalies and the occurrence frequency of MJO phases 1, 2, 3, 5, 6, and 8 are small and not significant (Figs. 2a-e,h), suggesting that the connection at interannual time scales between the occurrence frequencies of these MJO phases and wave activity is weak.

A transient experiment (E1) is performed with WACCM4 to further confirm the above correlation, using natural and anthropogenic external forcings, including spectrally resolved solar variability (Lean et al. 2005), time-varying greenhouse gases (GHGs) (from scenario A1B of IPCC 2001), volcanic aerosols [from the Stratospheric Processes and their Role in Climate (SPARC) Chemistry-Climate Model Validation (CCMVal) REF-B2 scenario recommendations], and a nudged QBO (the time series in CESM is determined from the observed climatology over the period 19552005). E1 is a historical simulation integrated over the period 1955-2005. All the forcing data used in this study are available from the CESM model input data repository. Note that previous studies have pointed out that the simulated MJO strength in WACCM is underestimated (Inness et al. 2003; Zhang et al. 2006; Subramanian et al. 2011; Liu et al. 2015; Yang et al. 2017; Kang and Tziperman 2017). However, these studies also pointed out that the CAM-based WACCM, like most atmospheric general circulation models, can reproduce the eastward-propagating intraseasonal zonal winds and OLR in the tropical Indian and Pacific Oceans and the responses to $\mathrm{MJO}$ in the troposphere and stratosphere. These previous studies indicated that WACCM has the ability to simulate MJO activity, but the simulated intensity of MJO activity is relative weaker than the observation.

The results show that the correlation between the observed occurrence frequencies of the eight MJO phases and the northern extratropical stratospheric wave activity anomalies (Fig. 2) is well simulated by the WACCM4 model (Fig. 4) for the period 1960-2005 (the first 5 years are for the spinup period). That is, the northern extratropical stratospheric E-P flux divergence anomalies have the strongest correlation with the occurrence frequency of MJO phase 4 (Fig. $4 \mathrm{~g}$ ) and are anticorrelated with MJO phase 7 (Fig. 4f).

To obtain more evidence of the potential influence of MJO phases 4 and 7 on the northern winter extratropical stratosphere, we defined MJO phases 4 and 7 occurrence-frequency indices (Fig. 5). These indices were calculated by removing the mean from the occurrence-frequency time series of the MJO phases 4 and 7 in winter (the red lines in Figs. $2 \mathrm{~g}, \mathrm{f}$ ). A positive value of the index indicates a high-frequency year for MJO phase 4 or 7, whereas a negative value indicates a low-frequency year. Figure 5 shows the interannual variability of the indices of MJO phases 4 and 7. It is interesting that MJO phase 4 has a low occurrence frequency in the 1980s but a high occurrence frequency in the 1990s, while the variation of MJO phase 7 is generally opposite to that of MJO phase 4 . These two time series show a negative correlation $(R=-0.41$, significant at the $95 \%$ confidence level). This interesting phenomenon deserves future investigation.

The composite anomalies of the E-P flux, E-P flux divergence, and zonal-mean temperature from the NCEP-NCAR reanalysis data for high- and lowoccurrence-frequency years of MJO phases 4 and 7 during winter for the period 1979-2013 in the northern extratropical stratosphere are shown in Fig. 6. In winters with a high occurrence frequency of MJO phase 4 (Fig. 6a), the weakened upward wave fluxes and stronger E-P flux divergence anomalies in the middle and upper stratosphere at middle and high latitudes imply depressed wave activity, and this is accompanied by negative temperature anomalies in the same region. Conversely, in winters with a low occurrence frequency of MJO phase 4 (Fig. 6b), the enhanced upward wave fluxes and stronger E-P flux convergence imply enhanced wave activity and positive temperature anomalies. As expected, the changes in upward wave fluxes, E-P flux divergence, and zonal-mean temperature in the middle and upper stratosphere at middle and high latitudes associated with MJO phase 7 are just the opposite 



FIG. 4. As in Fig. 2, but from the WACCM4 experiment (E1).

of those associated with MJO phase 4 (Figs. 6c,d). Note that the modulation of the E-P flux during MJO phase 4 is more noticeable than that during $\mathrm{MJO}$ phase 7, which is consistent with the correlation analysis (Figs. $2 \mathrm{~g}, \mathrm{f}$ ).

\section{Mechanism by which the MJO affects the northern extratropical stratosphere}

It has been demonstrated that tropical forcing can influence the stratospheric polar vortex by modulating the PNA teleconnection pattern in the Northern Hemisphere (Garfinkel and Hartmann 2008; Xie et al. 2012). Subsequently, the wave trains in the upper troposphere can enhance planetary wave propagation into the subpolar stratosphere, which weakens the stratospheric polar vortex. Further investigation is required as to whether the anomalies in the stratospheric circulation and temperature associated with high- and lowoccurrence-frequency years of MJO phases 4 and 7 are also tied to teleconnection pattern and corresponding wave activity in the upper troposphere.

To illuminate the connection between tropical MJO phases 4 and 7 and northern extratropical stratospheric wave activity, Fig. 7 shows the geopotential height anomalies at $200 \mathrm{hPa}$ during the high- and low-occurrence-frequency years of MJO phases 4 and 7. The geopotential height anomalies were again calculated by removing the seasonal cycle and then applying a 100-day high-pass digital filter to the daily data. As suggested by Seo and Son (2012), anomalous tropical heating related to the MJO results in the Rossby wave train traveling north from the forcing region to the northern Pacific and North America, then turning south toward the equatorial African continent. Figures $7 \mathrm{a}$ and $7 \mathrm{~b}$ show opposite pattern of geopotential height anomalies in the high- and lowoccurrence-frequency years of MJO phase 4. This pattern resembles a Rossby wave train traveling north toward the northern Pacific and North America, and 

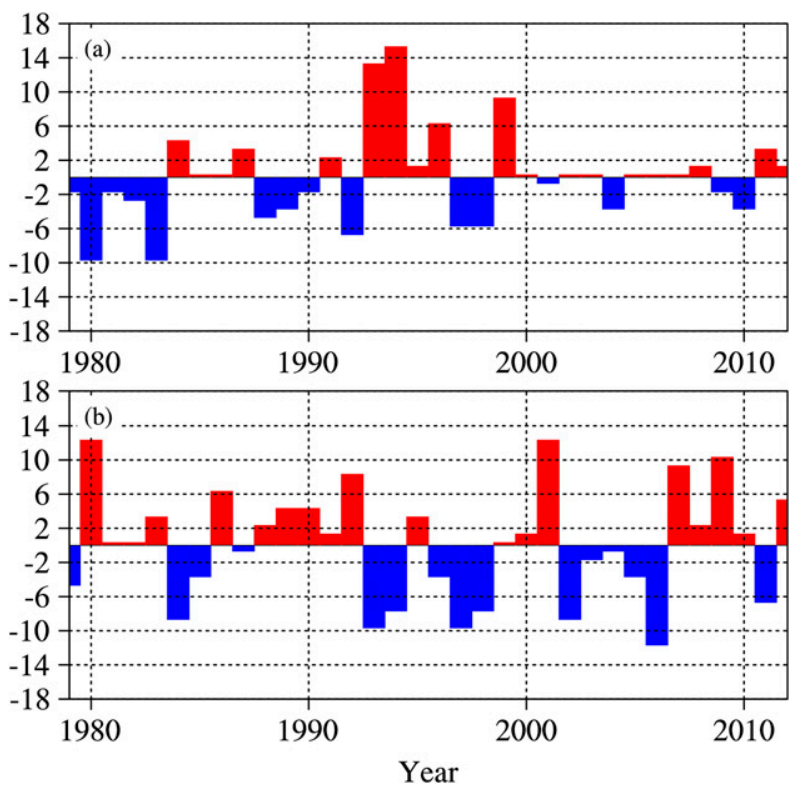

FIG. 5. MJO phases (a) 4 and (b) 7 occurrence-frequency indices. The indices were calculated by removing the mean from the occurrence-frequency time series of the MJO phases 4 and 7 in winter (please refer to Fig. 2).

then turning south toward the African continent. The spatial structure of the Rossby wave train is similar to that in the PNA pattern. Figures $7 \mathrm{c}$ and $7 \mathrm{~d}$ are the same as in Figs. 7a and 7b, but for MJO phase 7. The pattern of geopotential height anomalies in years with high and low occurrence frequency of MJO phase 7 is generally opposite to that of MJO phase 4. As the intensity of the convection anomalies at the center of the OLR anomalies during MJO phase 4 is larger than during MJO phase 7 (Fig. 3), the geopotential height anomalies in MJO phase 7 (Figs. 7c,d) are smaller than in MJO phase 4 (Figs. 7a,b).

To examine the horizontal structures of planetary wave anomalies, Fig. 7 also shows the climatological stationary waves of wavenumber 1 accompanied by the geopotential height anomalies. There is a positive (negative) anomaly superimposed on the Aleutian low over the northern Pacific during the high- (low-) occurrence-frequency years of MJO phase 4 . This would lead to a weakened (strengthened) tropospheric wave forcing of wavenumber 1 . The teleconnections and poleward traveling of Rossby wave in the upper troposphere can, in turn, alter planetary wave propagation into the subpolar stratosphere, where the waves dissipate, decelerating the stratospheric polar vortex (Garfinkel and Hartmann 2008).

Combining Figs. 6 and 7, the mechanism by which the MJO affects the northern extratropical stratospheric planetary wave can be summarized as follows: the propagation of tropical Rossby waves to middle and high latitudes is triggered in both the high- and low-occurrence-frequency years of MJO phase 4 .
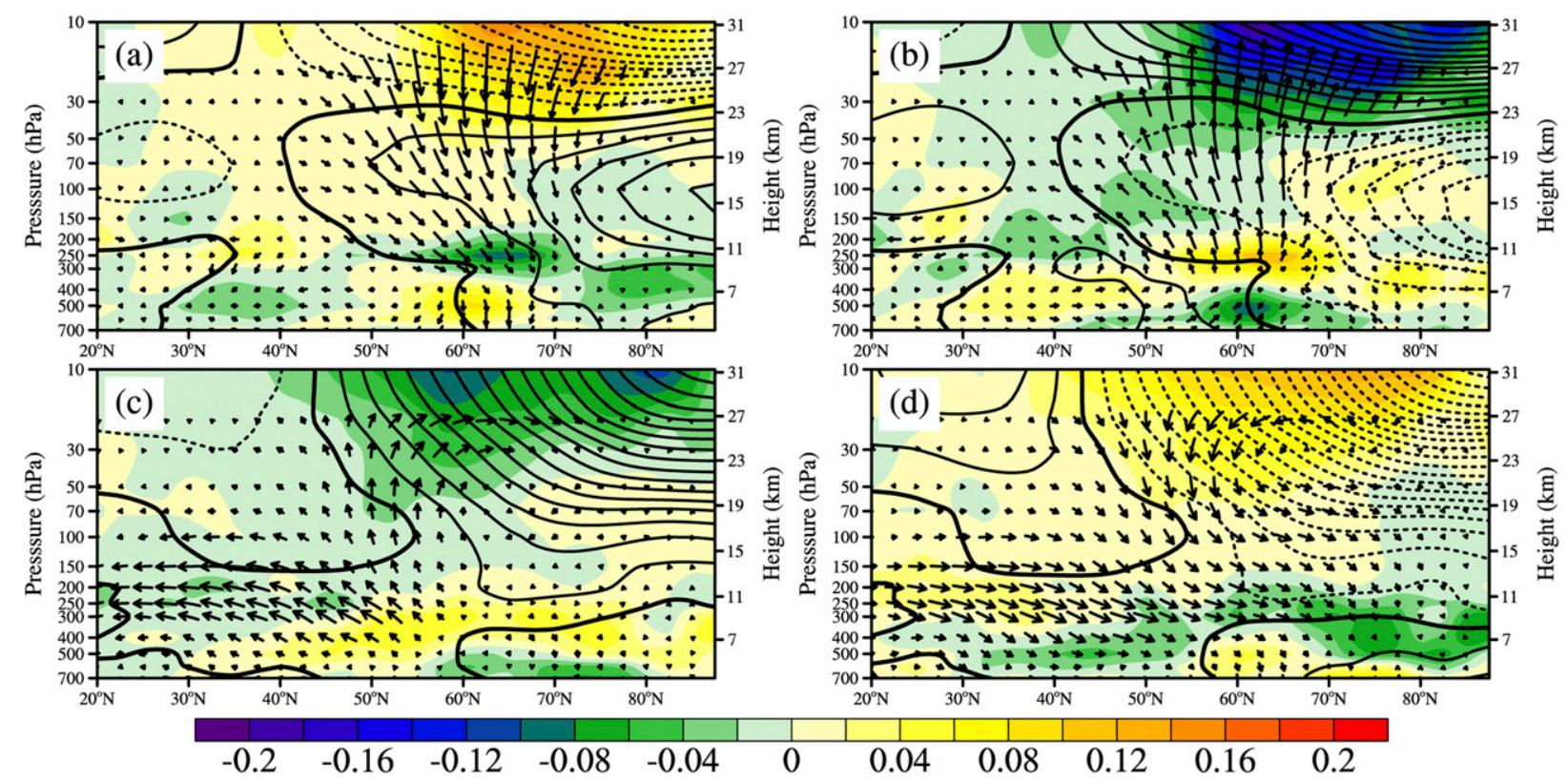

FIG. 6. Latitude-height cross sections of composite E-P flux (vectors; horizontal term: $10^{7} \mathrm{~m}^{3} \mathrm{~s}^{-2}$ and vertical term: $10^{5} \mathrm{~Pa} \mathrm{~m}^{2} \mathrm{~s}{ }^{-2}$ ), E-P flux divergence (shaded; $\mathrm{m} \mathrm{s}^{-1} \mathrm{day}^{-1}$ ), and zonal-mean temperature (contours; K) anomalies during (a), (c) high- and (b), (d) lowoccurrence-frequency years of MJO phases (a),(b) 4 and (c),(d) 7. Solid contours are positive, dashed contours are negative, and zero contours are thickened. Contour interval for the zonal-mean temperature anomalies is $0.02 \mathrm{~K}$. 



FIG. 7. Geopotential height (contours; gpm) anomalies during the (a),(c) high- and (b),(d) low-occurrencefrequency years of MJO phases (a),(b) 4 and (c),(d) 7 at $200 \mathrm{hPa}$ associated with winter-averaged stationary waves of wavenumber 1 (shaded) from the NCEP-NCAR reanalysis data. The geopotential height anomalies were also calculated by removing the daily seasonal cycle and then applying a 100-day high-pass digital filter to the daily data. Solid contours are positive, and dashed contours are negative. Contour interval for the geopotential height anomalies is $0.6 \mathrm{gpm}$.

However, the anomalous waves during the high- (low-) occurrence-frequency years of MJO phase 4 (Figs. 7a,b, the geopotential height anomalies) are out of phase (in phase) with the climatological stationary wavenumber 1 in the Northern Hemisphere. This wave interference leads to weakened (strengthened) planetary waves along the polar waveguide during the high- (low-) frequency periods of MJO phase 4. Under this condition, it is expected that fewer (more) planetary waves propagate vertically into the stratosphere when the occurrence frequency of the MJO phase 4 is high (low). This explains why there is less (more) E-P flux and positive (negative) E-P flux divergence anomalies during the years with high (low) occurrence frequency of MJO phase 4 (Figs. 6a,b). The above processes are reversed for MJO phase 7.

We now use Rossby wave ray tracing to further trace the trajectory of the Rossby wave trains described above. The ray paths of waves with wavenumbers $1-3$ at $200 \mathrm{hPa}$ generated by the perturbed circulation over the region $20^{\circ} \mathrm{S}-20^{\circ} \mathrm{N}, 70^{\circ}-150^{\circ} \mathrm{E}$ in winter are shown in Fig. 8. The wave ray paths represent the climate teleconnections (i.e., the propagation of stationary waves in realistic flows). The method for calculating the wave ray paths and application of the barotropic model are described in detail by Li et al. (2015) and Zhao et al. (2015). We found that some planetary waves generated by the perturbed circulation over this region, where there are strong convection anomalies in MJO phase 4, travel north to the northern $\mathrm{Pa}$ cific and North America, and then turn south toward the African continent. This suggests the possibility that Rossby waves generated by a convection anomaly in the tropics related to MJO phase 4 may travel along the ray trajectories to the Northern Hemisphere middle and high latitudes. Thus, it can be expected that some wave ray paths are in agreement with the composite patterns of the geopotential height anomalies in Fig. 7.

Figure 9 shows the corresponding vertical structures of the MJO-induced planetary waves that propagate into the stratosphere. The geopotential height anomalies in the northern extratropics during the high- (low-) occurrence-frequency years of MJO phase 4 generally tilt to the west with height and are in the opposite (same) phase as the climatological wavenumber 1, and this generates destructive (constructive) interference between the MJO-induced waves and the background stationary waves (Figs. 9a,b). Thus, the weakened (enhanced) wave activity in the northern extratropical stratosphere corresponding to the high (low) occurrence frequency of MJO phase 4 can be expected. This result is associated with anomalous upward wave flux and E-P flux divergence at middle and high latitudes in the Northern Hemisphere middle and upper stratosphere and accompanied by the temperature anomalies during



FIG. 8. Ray paths (green lines) at $200 \mathrm{hPa}$ in winter. Black crosses denote wave sources in the region $20^{\circ} \mathrm{S}-20^{\circ} \mathrm{N}, 70^{\circ}-150^{\circ} \mathrm{E}$. Rays with wavenumbers $1-3$ are shown. The shading indicates meridional gradient of quasigeostrophic potential vorticity $\left(\mathrm{K} \mathrm{kg}^{-1} \mathrm{~m} \mathrm{~s}^{-1}\right)$. 

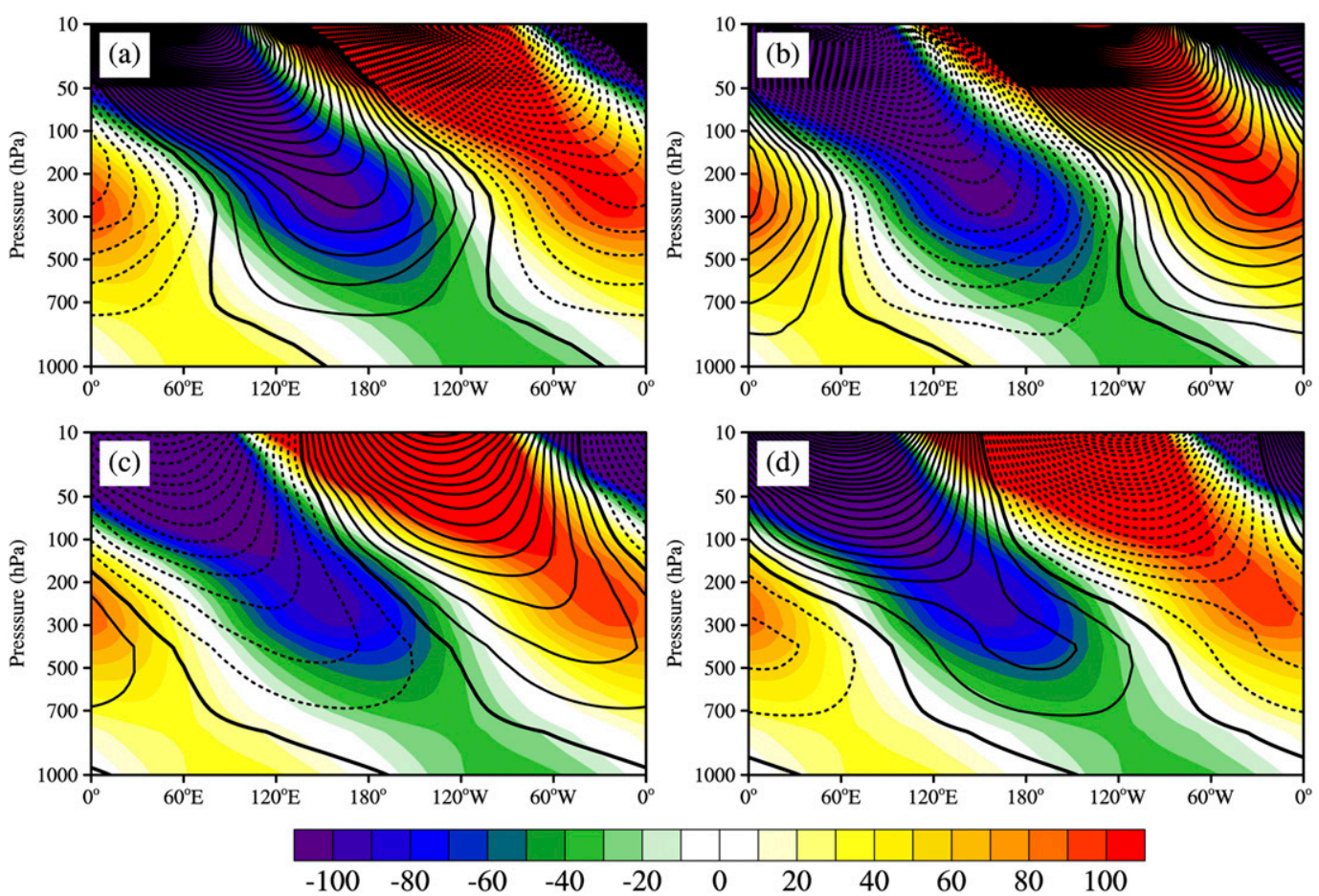

FIG. 9. Longitude-height cross sections of the spatially averaged $\left(45^{\circ}-75^{\circ} \mathrm{N}\right)$ geopotential height anomalies (contours; gpm) during (a),(c) high- and (b),(d) low-occurrence-frequency years of MJO phases (a),(b) 4 and (c),(d) 7 with winter-averaged stationary waves of wavenumber 1 (shaded) from the NCEP-NCAR reanalysis data. Solid contours are positive, dashed contours are negative, and zero contours are thickened. Contour interval for the geopotential height anomalies is $0.2 \mathrm{gpm}$.

winter seen in Figs. 6a and 6b. MJO phase 7 has the opposite effect on the background wavenumber 1 to MJO phase 4 (Figs. 9c,d).

We also examined the responses of wavenumbers 2 and 3 to high (low) occurrence frequency of MJO phases 4 and 7 (Fig. 10). The anomalous waves of wavenumber 2 in geopotential height anomalies during the highand low-occurrence-frequency years of MJO phase 4 do not overall superpose on the climatological stationary waves of wavenumber 2 in the vertical in the northern extratropics. There is an overall in-phase superposition between the anomalous wavenumber- 3 waves and climatological stationary waves of wavenumber 3 ; however, the phases are opposite to those of wavenumber 1 during the high- and low-occurrence-frequency years of MJO phase 4. In MJO phase 7, the anomalous waves of wavenumber 2 and 3 in geopotential height anomalies during the high- and low-occurrence-frequency years do not overall superpose on climatological stationary waves of wavenumber 2 and 3 in the vertical in the northern extratropics. Therefore, only the wavenumber-1 responses to MJO in geopotential height anomalies are able to explain the stratospheric wave activity anomalies during the high- and low-occurrence-frequency years of MJO phases 4 and 7.
At this stage, a question is raised: Why do only the occurrence frequencies of MJO phase 4 and MJO phase 7 have a significant influence on wave activity in the northern extratropical stratosphere. Here, we further examine the effects of other MJO phases on wave activity in the extratropics. Figure 11 shows the geopotential height anomalies at $200 \mathrm{hPa}$ during the high- and lowoccurrence-frequency years of MJO phases 1, 2, 3, 5, 6, and 8 . It is apparent that the PNA-like wave trains that propagate poleward to middle and high latitudes also develop during the high- and low-occurrence-frequency years of these MJO phases. However, it can be seen from Fig. 12 that the geopotential height anomalies during the high- and low-occurrence-frequency years of MJO phases 1, 2, 3, 5, 6, and 8 do not overall superpose on stationary waves of wavenumber 1 in the vertical in the extratropics. This illustrates that anomalous waves caused by these MJO phases do not efficiently interfere with the stationary waves of wavenumber 1 ; consequently, the occurrence frequency of MJO phases 1, 2,3, 5,6 , and 8 have no significant influence on the wave activity of wavenumber 1 in the northern extratropical stratosphere.

Figure 13 shows the wavenumber- 2 geopotential height anomalies during the high and low occurrence frequencies 
MJO Phase 4
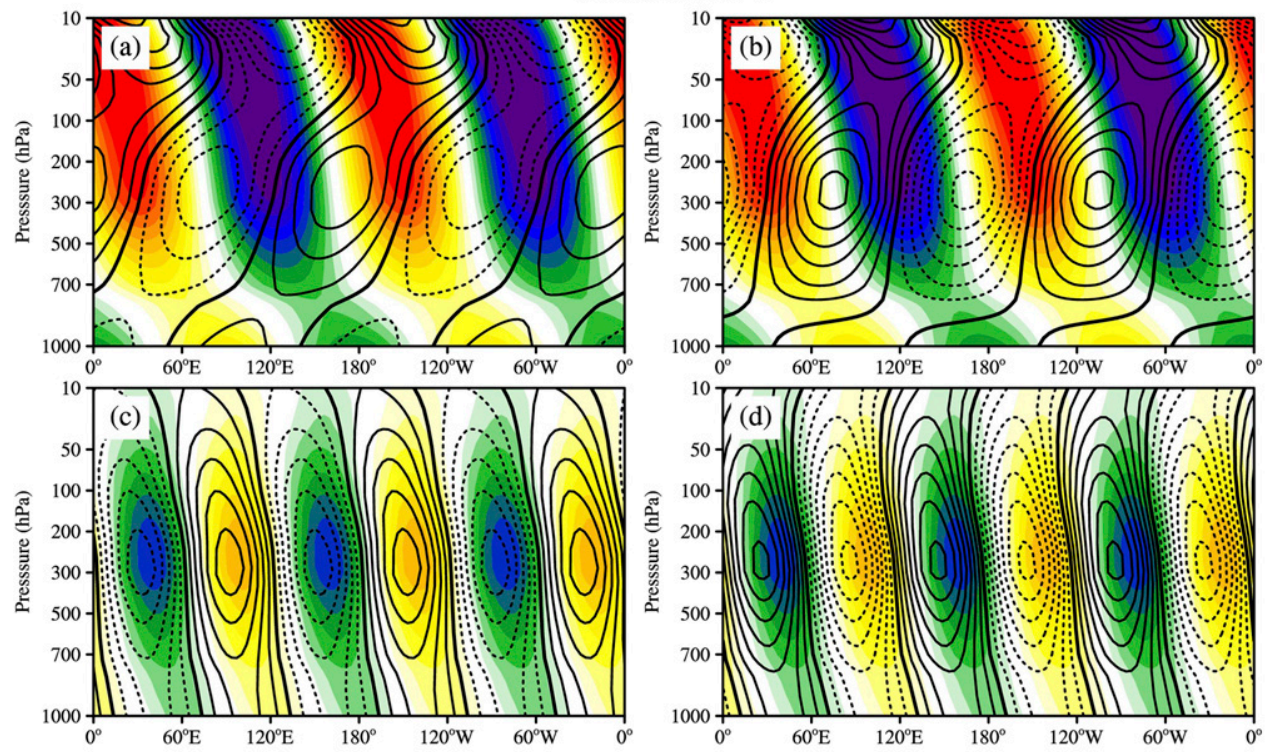

90

80

70

60

50

40

30

20

MJO Phase 7
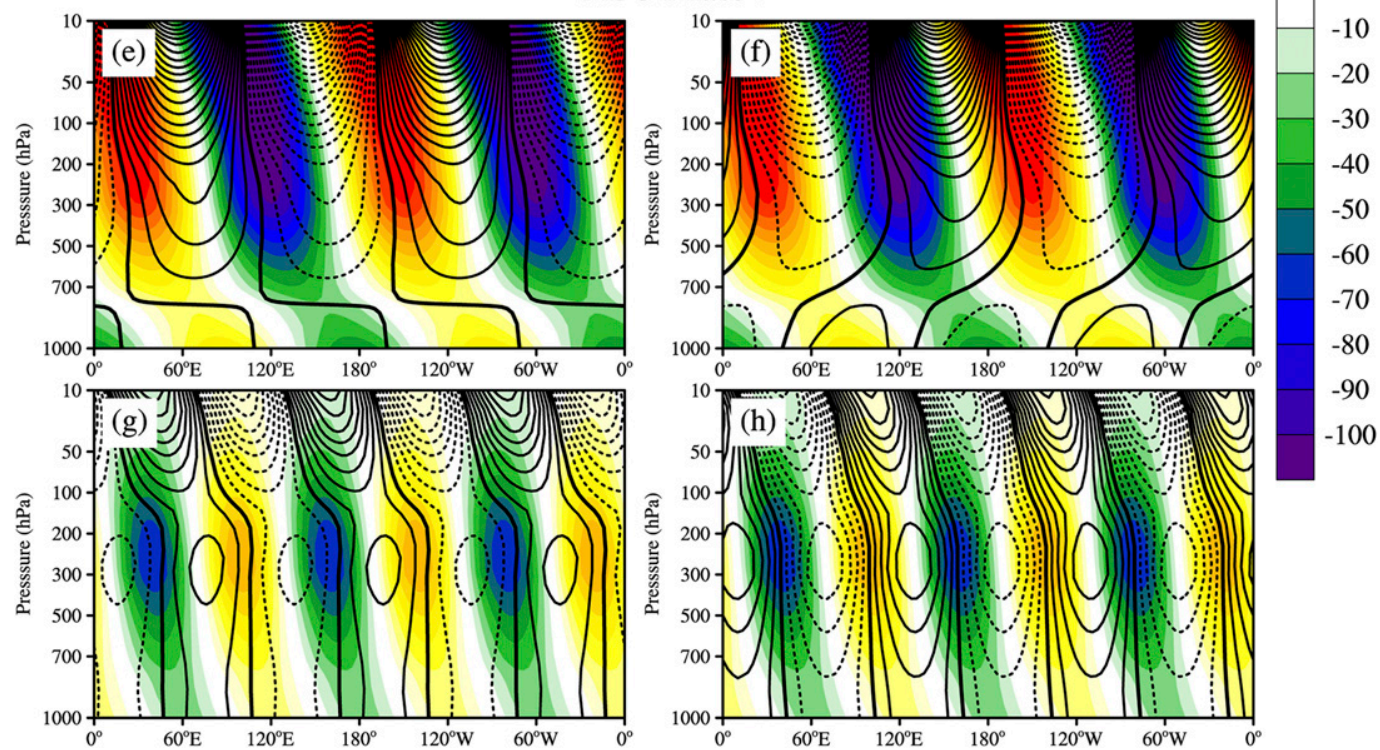

FIG. 10. As in Fig. 9, but for the wavenumbers (a),(b),(e),(f) 2 and (c),(d),(g),(h) 3 .

of MJO phases 1, 2, 3, 5, 6, and 8. The anomalous waves of wavenumber 2 during the high- and low-occurrencefrequency years of MJO phases 2, 3, 5, and 6 do not overall superpose on the climatological stationary waves of wavenumber 2 in the northern extratropics; nonetheless, the influence of MJO phases 1 and 8 on wavenumber 2 cannot be neglected. This suggests that wavenumber 2 can be weakened (strengthened) in the high- (low-) occurrence-frequency years of MJO phases 1 and 8 . Figure 14 is the same as Fig. 13, but for wavenumber 3. The anomalous wavenumber-3 geopotential height anomalies during the high- and low-occurrence-frequency years of MJO phases $1,2,6$, and 8 do not overall superpose on the climatological stationary waves of wavenumber 3 in the northern extratropics. However, the geopotential height anomalies in the northern extratropics during the high- (low-) occurrence-frequency years of MJO phase 3 are in the opposite (same) phase as the background wavenumber 3 , weakening (enhancing) the strength of wavenumber 3 . MJO phase 5 has the opposite effect on the background wavenumber 3 to MJO phase 3.

Figures 13 and 14 suggest that the impacts of wavenumbers 2 and 3 on interannual variations in stratospheric 

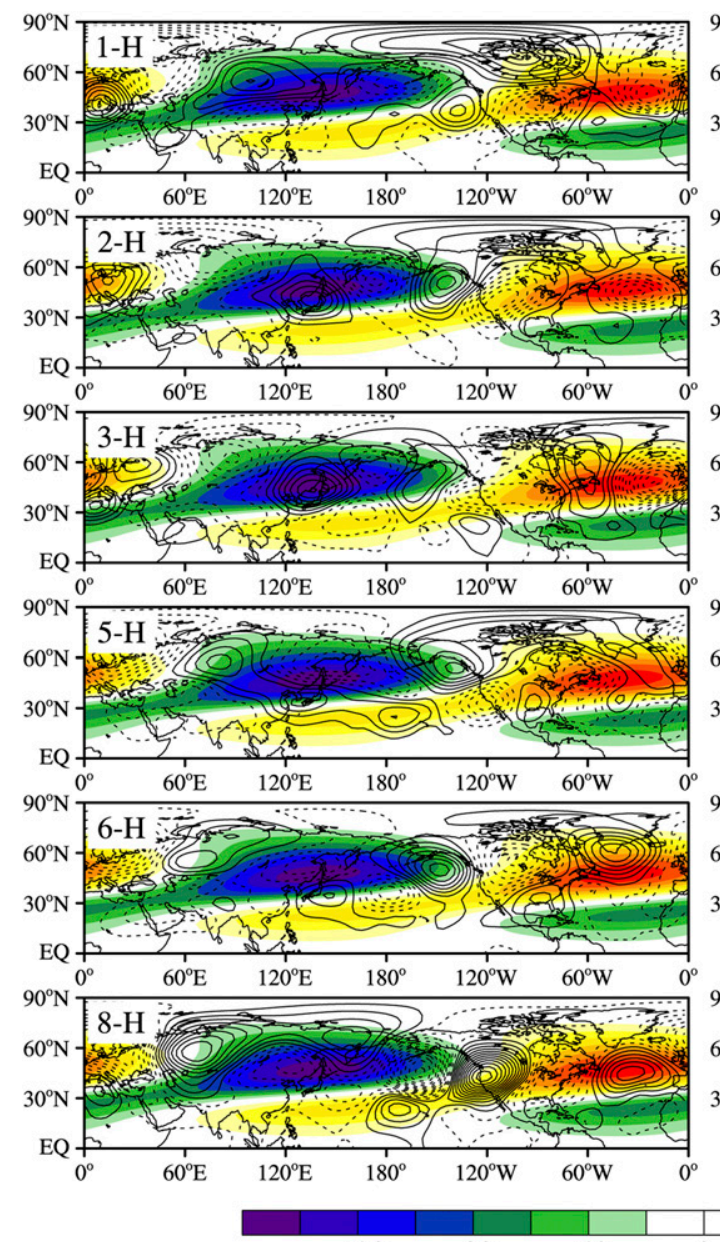

$-120 \quad-80$
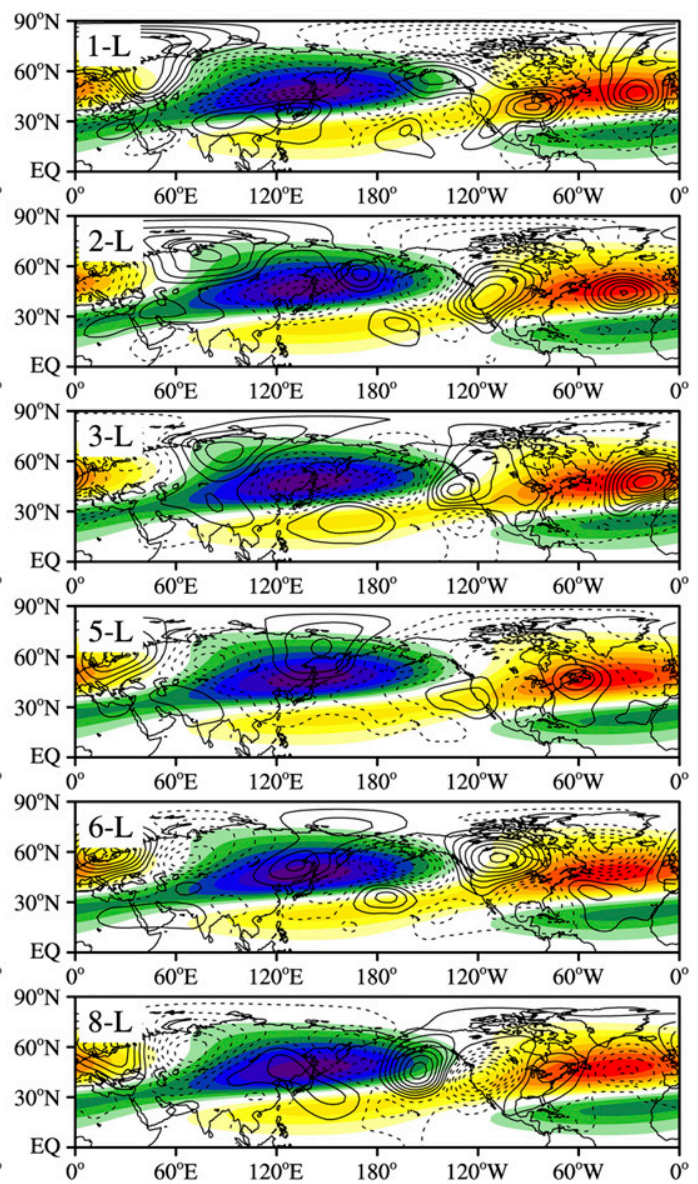

$\begin{array}{llll}0 & 40 & 80 & 120\end{array}$

FIG. 11. As in Fig. 7, but for (top)-(bottom) MJO phases 1, 2, 3, 5, 6, and 8 .

wave activity can be triggered by MJO phases $1,3,5$, or 8 . However, the correlation coefficients between the E-P flux divergence anomalies and the occurrence frequency of MJO phases 1, 3, 5, and 8 are small and not significant (Fig. 2). In addition, previous studies have recognized that wavenumber-1 disturbances caused by the MJO are the dominant waves that propagate into the winter stratosphere and subsequently weaken the polar vortex (Garfinkel et al. 2012b, 2014). Thus, the wavenumber-1 responses to MJO phases can explain a large part of the variability in the stratospheric wave activity during the high- and low-occurrence-frequency years of eight MJO phases.

\section{Conclusions}

The effect of the MJO on wave activity in the extratropical stratosphere has been reported in several previous studies (Garfinkel et al. 2012b, 2014). However, these studies focused mainly on the relationship between these two processes over intraseasonal time scales. The present study has investigated the relationship between the occurrence frequency of the individual phases of the MJO and the interannual variability of stratospheric high-frequency wave activity in Northern Hemisphere middle and high latitudes during winter over the period 1979-2013.

We have found a significant positive correlation between the occurrence frequency of MJO phase 4 and E-P flux divergence anomalies; that is, higher (lower) occurrence frequency of MJO phase 4 corresponds to weaker (stronger) upward wave fluxes and increased (decreased) E-P flux divergence anomalies at middle and high latitudes in the middle and upper stratosphere. This implies depressed (enhanced) wave activity accompanied by a stronger (weaker) polar vortex in this region. During MJO phase 4, an anomalous PNA-like Rossby wave train is generated that travels north to the middle and high latitudes in the northern extratropical troposphere, and the geopotential height anomalies in 

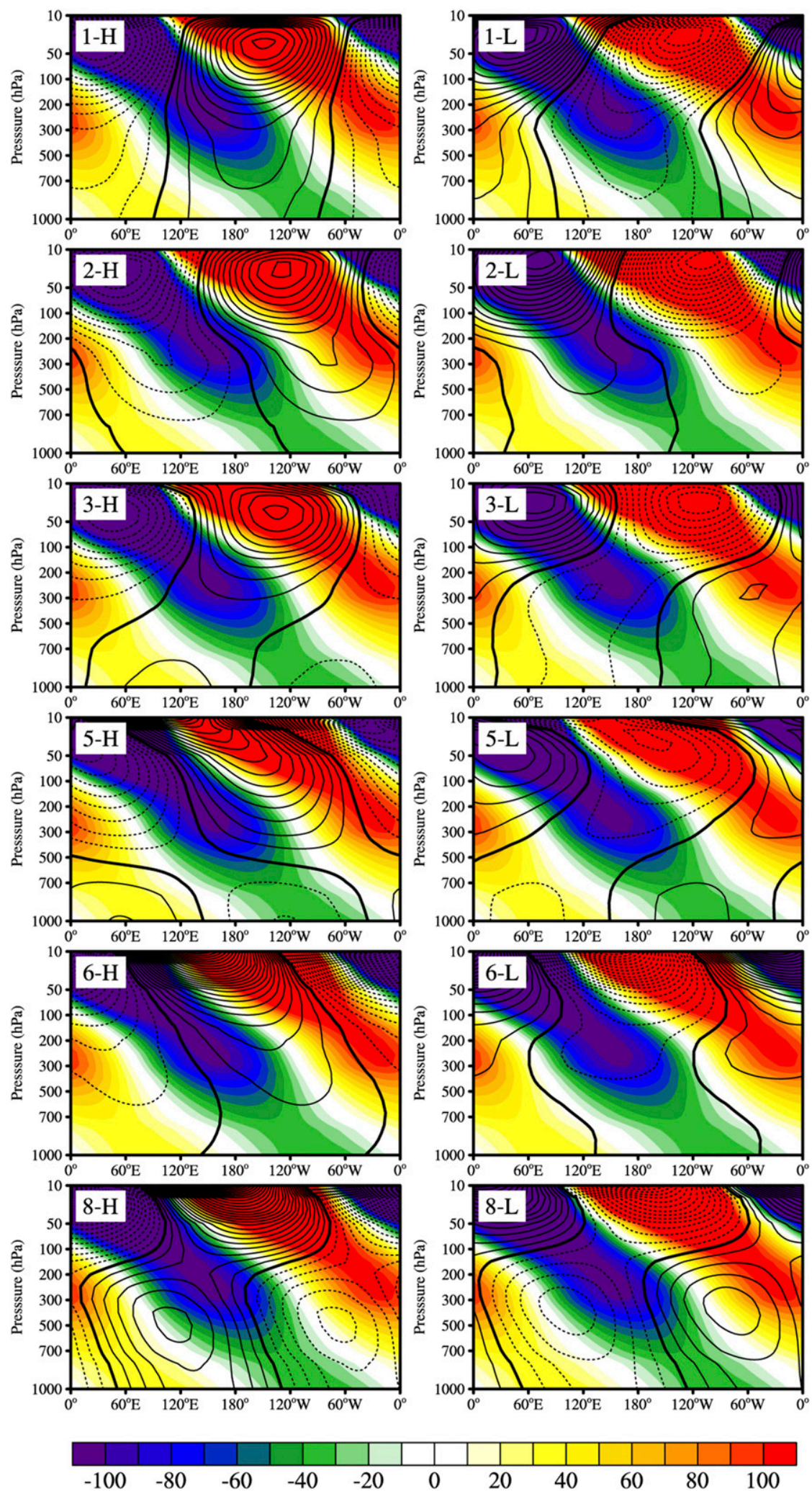

FIG. 12. As in Fig. 9, but for (top)-(bottom) MJO phases 1, 2, 3, 5, 6, and 8. 

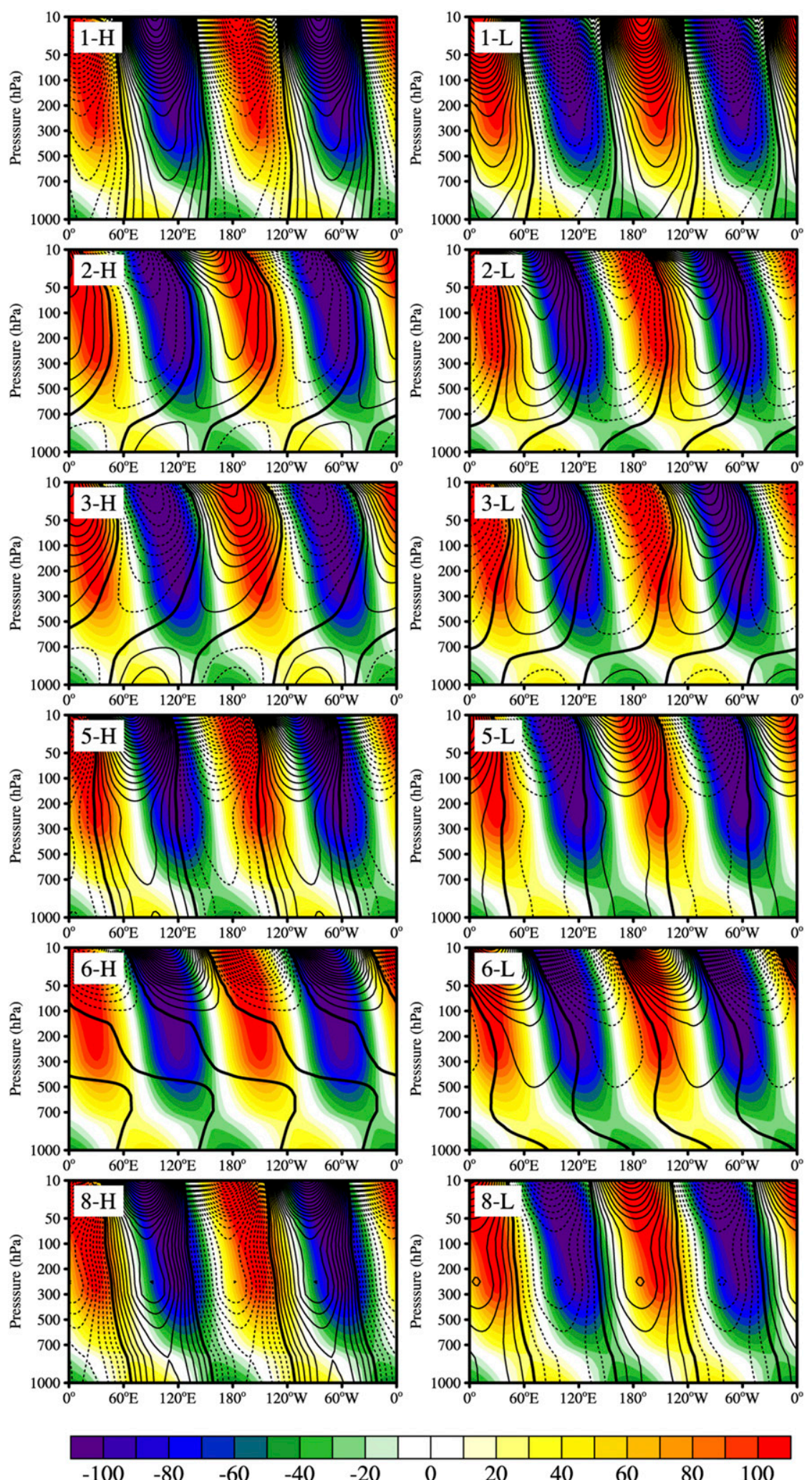

FIG. 13. As in Fig. 12, but for wavenumber 2. 

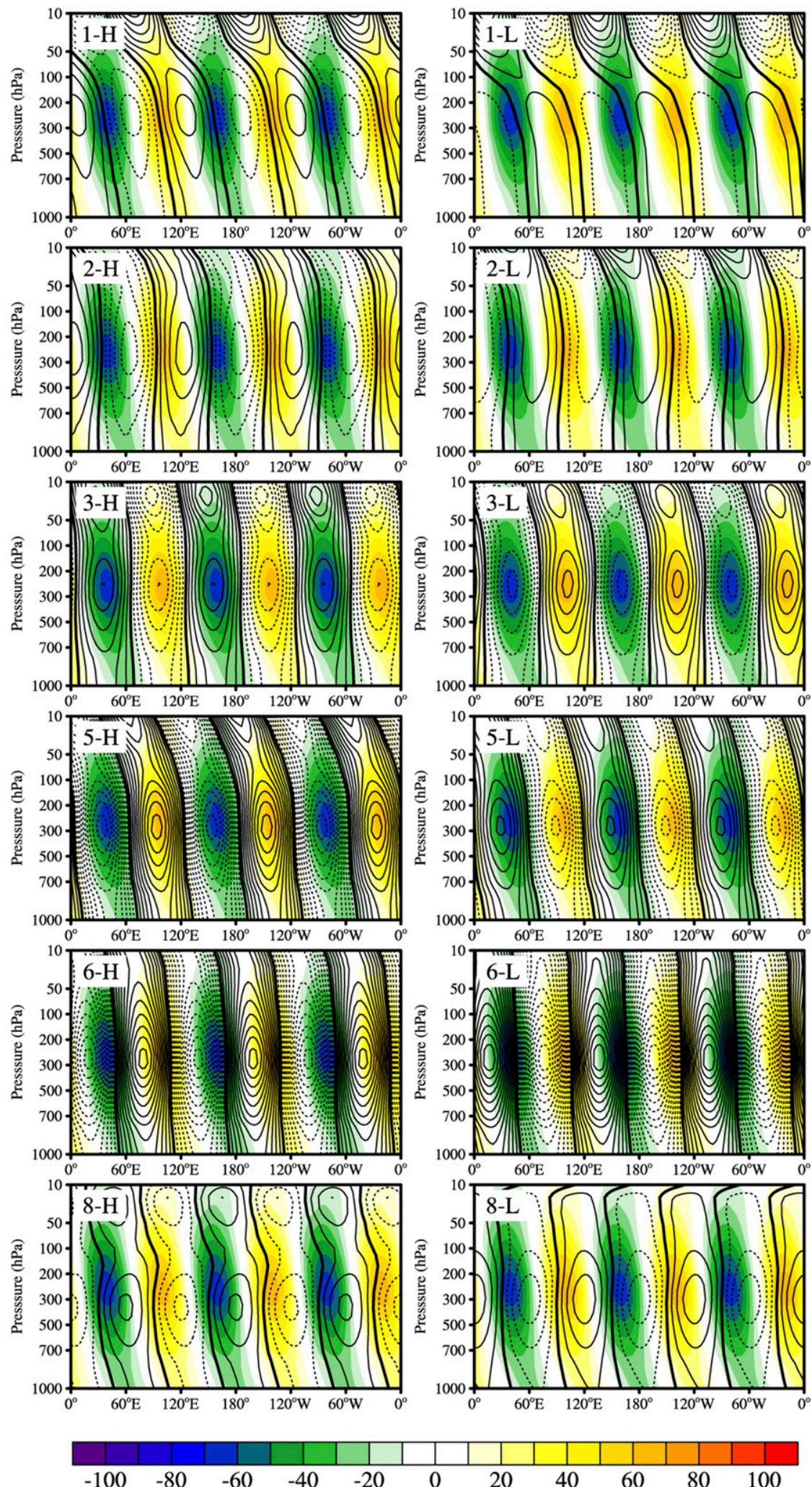

FIG. 14. As in Fig. 12, but for wavenumber 3. 
the high- (low-) occurrence-frequency years of MJO phase 4 are of the opposite (same) phase as the background wavenumber 1 in the vertical in the northern extratropics. The pattern of convection anomaly during MJO phase 7 is approximately opposite to that during MJO phase 4, consequently, the responses of wavenumber 1 to high and low occurrence frequencies of MJO phase 7 are opposite to that of MJO phase 4 . As MJO phase 7 has weaker convection anomalies, the effect of MJO phase 7 on the wave activity in the northern extratropical stratosphere is weaker than that of MJO phase 4 . The anomalous waves in the geopotential height field caused by MJO phases 1, 2, 3, 5, 6, and 8 are not overally superposed on the climatological waves of wavenumber 1 , and the wave interference between them is inefficient. Therefore, MJO phases 1, 2, 3, 5, 6, and 8 have no significant influence on the wave activity in the northern extratropical stratosphere.

Acknowledgments. This work was supported by the National Science Foundation of China (41630421, 41575038, and 41575039). We thank the Australian Bureau of Meteorology for providing the MJO index, and NOAA for providing the OLR data and OOMI. We would also thank the NCEP-NCAR and ECMWF for providing the reanalysis data. We thank the three anonymous reviewers for their helpful comments, which significantly improved the quality of the paper.

\section{REFERENCES}

Andrews, D. G., J. R. Holton, and C. B. Leovy, 1987: Middle Atmosphere Dynamics. Academic Press, 489 pp.

Butchart, N., and Coauthors, 2006: Simulations of anthropogenic change in the strength of the Brewer-Dobson circulation. Climate Dyn., 27, 727-741, https://doi.org/10.1007/s00382-006-0162-4.

Cagnazzo, C., and E. Manzini, 2009: Impact of the stratosphere on the winter tropospheric teleconnections between ENSO and the North Atlantic and European region. J. Climate, 22, 1223 1238, https://doi.org/10.1175/2008JCLI2549.1.

_ , and Coauthors, 2009: Northern winter stratospheric temperature and ozone responses to ENSO inferred from an ensemble of chemistry climate models. Atmos. Chem. Phys., 9 , 8935-8948, https://doi.org/10.5194/acp-9-8935-2009.

Calvo Fernández, N., R. R. García, R. García Herrera, D. Gallego Puyol, L. Gimeno Presa, E. Hernández Martín, and P. Ribera Rodríguez, 2004: Analysis of the ENSO signal in tropospheric and stratospheric temperatures observed by MSU, 1979-2000. J. Climate, 17, 3934-3946, https://doi.org/10.1175/15200442(2004)017<3934:AOTESI > 2.0.CO;2.

— M. A. Giorgetta, R. G. Herrera, and E. Manzini, 2009: Nonlinearity of the combined warm ENSO and QBO effects on the Northern Hemisphere polar vortex in MAECHAM5 simulations. J. Geophys. Res., 114, D13109, https://doi.org/ 10.1029/2008JD011445.

Camp, C. D., and K.-K. Tung, 2007: Stratospheric polar warming by ENSO in winter: A statistical study. Geophys. Res. Lett., 34, L04809, https://doi.org/10.1029/2006GL028521.
Cassou, C., 2008: Intraseasonal interaction between the MaddenJulian oscillation and the North Atlantic Oscillation. Nature, 455, 523-527, https://doi.org/10.1038/nature07286.

Chen, X., J. Ling, and C. Li, 2016: Evolution of the Madden-Julian oscillation in two types of El Niño. J. Climate, 29, 1919-1934, https://doi.org/10.1175/JCLI-D-15-0486.1.

Cohen, J., and J. Jones, 2011: A new index for more accurate winter predictions. Geophys. Res. Lett., 38, L21701, https://doi.org/ 10.1029/2011GL049626.

Dee, D. P., and Coauthors, 2011: The ERA-Interim reanalysis: Configuration and performance of the data assimilation system. Quart. J. Roy. Meteor. Soc., 137, 553-597, https://doi.org/10.1002/qj.828.

Deng, L., T. Li, J. Liu, and M. Peng, 2016: Factors controlling the interannual variations of MJO intensity. J. Meteor. Res., 30, 328-340, https://doi.org/10.1007/s13351-016-5113-3.

Edmon, H. J., Jr., B. J. Hoskins, and M. E. McIntyre, 1980: EliassenPalm cross sections for the troposphere. J. Atmos. Sci., 37, 26002616, https://doi.org/10.1175/1520-0469(1980)037<2600: EPCSFT $>2.0 . \mathrm{CO} ; 2$.

Garcia, R. R., and W. J. Randel, 2008: Acceleration of the BrewerDobson circulation due to increases in greenhouse gases. J. Atmos. Sci., 65, 2731-2739, https://doi.org/10.1175/2008JAS2712.1.

- D. R. Marsh, D. E. Kinnison, B. A. Boville, and F. Sassi, 2007: Simulation of secular trends in the middle atmosphere, 19502003. J. Geophys. Res., 112, D09301, https://doi.org/10.1029/ 2006JD007485.

Garfinkel, C. I., and D. L. Hartmann, 2008: Different ENSO teleconnections and their effects on the stratospheric polar vortex. J. Geophys. Res., 113, D18114, https://doi.org/10.1029/ 2008JD009920.

, T. A. Shaw, D. L. Hartmann, and D. W. Waugh, 2012a: Does the Holton-Tan mechanism explain how the quasi-biennial oscillation modulates the Arctic polar vortex? J. Atmos. Sci., 69, 1713-1733, https://doi.org/10.1175/JAS-D-11-0209.1.

- S. B. Feldstein, D. W. Waugh, C. Yoo, and S. Lee, 2012b: Observed connection between stratospheric sudden warmings and the Madden-Julian oscillation. Geophys. Res. Lett., 39, L18807, https://doi.org/10.1029/2012GL053144.

_ J. J. Benedict, and E. D. Maloney, 2014: Impact of the MJO on the boreal winter extratropical circulation. Geophys. Res. Lett., 41, 6055-6062, https://doi.org/10.1002/2014GL061094.

_ M. M. Hurwitz, and L. D. Oman, 2015: Effect of recent sea surface temperature trends on the Arctic stratospheric vortex. J. Geophys. Res. Atmos., 120, 5404-5416, https://doi.org/10.1002/ 2015JD023284.

Gill, A. E., 1980: Some simple solutions for heat-induced tropical circulation. Quart. J. Roy. Meteor. Soc., 106, 447-462, https:// doi.org/10.1002/qj.49710644905.

Holland, M. M., D. A. Bailey, B. P. Briegleb, B. Light, and E. Hunke, 2012: Improved sea ice shortwave radiation physics in CCSM4: The impact of melt ponds and aerosols on Arctic sea ice. J. Climate, 25, 1413-1430, https://doi.org/10.1175/JCLI-D-11-00078.1.

Holton, J. R., and H.-C. Tan, 1980: The influence of the equatorial quasi-biennial oscillation on the global circulation at 50 mb. J. Atmos. Sci., 37, 2200-2208, https://doi.org/10.1175/ 1520-0469(1980)037<2200:TIOTEQ>2.0.CO;2.

, and - 1982: The quasi-biennial oscillation in the Northern Hemisphere lower stratosphere. J. Meteor. Soc. Japan, 60, 140-148, https://doi.org/10.2151/jmsj1965.60.1_140.

Hoskins, B. J., and D. J. Karoly, 1981: The steady linear response of a spherical atmosphere to thermal and orographic forcing. J. Atmos. Sci., 38, 1179-1196, https://doi.org/10.1175/ 1520-0469(1981)038<1179:TSLROA > 2.0.CO;2. 
_ and T. Ambrizzi, 1993: Rossby wave propagation on a realistic longitudinally varying flow. J. Atmos. Sci., 50, 1661-1671, https:// doi.org/10.1175/1520-0469(1993)050<1661:RWPOAR > 2.0.CO;2.

$\mathrm{Hu}$, Y., and K. K. Tung, 2003: Possible ozone-induced long-term changes in planetary wave activity in late winter. J. Climate, 16, 3027-3038, https://doi.org/10.1175/1520-0442(2003)016<3027: POLCIP $>2.0 . C O ; 2$.

Hurrell, J. W., and Coauthors, 2013: The Community Earth System Model: A framework for collaborative research. Bull. Amer. Meteor. Soc., 94, 1339-1360, https://doi.org/10.1175/ BAMS-D-12-00121.1.

Hurwitz, M. M., P. A. Newman, and C. I. Garfinkel, 2012: On the influence of North Pacific sea surface temperature on the Arctic winter climate. J. Geophys. Res., 117, D19110, https:// doi.org/10.1029/2012JD017819.

Inness, P. M., and J. M. Slingo, 2003: Simulation of the MaddenJulian oscillation in a coupled general circulation model. Part I: Comparison with observations and an atmosphereonly GCM. J. Climate, 16, 345-364, https://doi.org/10.1175/ 1520-0442(2003)016<0345:SOTMJO > 2.0.CO;2.

IPCC, 2001: Climate Change 2001: The Scientific Basis. Cambridge University Press, $881 \mathrm{pp}$.

Johnson, N. C., and S. B. Feldstein, 2010: The continuum of North Pacific sea level pressure patterns: Intraseasonal, interannual, and interdecadal variability. J. Climate, 23, 851-867, https:// doi.org/10.1175/2009JCLI3099.1.

Kalnay, E., and Coauthors, 1996: The NCEP/NCAR 40-Year Reanalysis Project. Bull. Amer. Meteor. Soc., 77, 437-471, https:// doi.org/10.1175/1520-0477(1996)077<0437:TNYRP>2.0.CO;2.

Kang, W., and E. Tziperman, 2017: More frequent sudden stratospheric warming events due to enhanced MJO forcing expected in a warmer climate. J. Climate, 30, 8727-8743, https:// doi.org/10.1175/JCLI-D-17-0044.1.

Karpechko, A. Y., and E. Manzini, 2012: Stratospheric influence on tropospheric climate change in the Northern Hemisphere. J. Geophys. Res., 117, D05133, https://doi.org/10.1029/ 2011JD017036.

Kim, B.-M., S.-W. Son, S.-K. Min, J.-H. Jeong, S.-J. Kim, X. Zhang, T. Shim, and J.-H. Yoon, 2014: Weakening of the stratospheric polar vortex by Arctic sea-ice loss. Nat. Commun., 5, 4646, https://doi.org/10.1038/ncomms5646.

Kuroda, Y., and K. Kodera, 1999: Role of planetary waves in the stratosphere-troposphere coupled variability in the Northern Hemisphere winter. Geophys. Res. Lett., 26, 2375-2378, https://doi.org/10.1029/1999GL900507.

Kushner, P. J., and L. M. Polvani, 2004: Stratospheretroposphere coupling in a relatively simple AGCM: The role of eddies. J. Climate, 17, 629-639, https://doi.org/10.1175/ 1520-0442(2004)017<0629:SCIARS $>2.0$. CO;2.

Lean, J., G. Rottman, J. Harder, and G. Kopp, 2005: SORCE contributions to new understanding of global change and solar variability. Sol. Phys., 230, 27-53, https://doi.org/10.1007/ s11207-005-1527-2.

L'Heureux, M. L., and R. W. Higgins, 2008: Boreal winter links between the Madden-Julian oscillation and the Arctic Oscillation. $J$. Climate, 21, 3040-3050, https://doi.org/10.1175/2007JCLI1955.1.

Li, K.-F., B. Tian, K. K. Tung, L. Kuai, J. R. Worden, Y. L. Yung, and B. L. Slawski, 2013: A link between tropical intraseasonal variability and Arctic stratospheric ozone. J. Geophys. Res. Atmos., 118, 4280-4289, https://doi.org/10.1002/jgrd.50391.

Li, Y., and J. Li, 2012: Propagation of planetary waves in the horizontal non-uniform basic flow (in Chinese). Chin. J. Geophys., $\mathbf{5 5}, 361-371$.
F. F. Jin, and S. Zhao, 2015: Interhemispheric propagation of stationary Rossby waves in a horizontally nonuniform background flow. J. Atmos. Sci., 72, 3233-3256, https://doi.org/10.1175/JAS-D-14-0239.1.

Lin, H., G. Brunet, and J. Derome, 2009: An observed connection between the North Atlantic Oscillation and the MaddenJulian oscillation. J. Climate, 22, 364-380, https://doi.org/ 10.1175/2008JCLI2515.1.

,-- , and B. Yu, 2015: Interannual variability of the MaddenJulian oscillation and its impact on the North Atlantic Oscillation in the boreal winter. Geophys. Res. Lett., 42, 5571-5576, https://doi.org/10.1002/2015GL064547.

Liu, C., B. Tian, K.-F. Li, G. L. Manney, N. J. Livesey, Y. L. Yung, and D. E. Waliser, 2014: Northern Hemisphere mid-winter vortex-displacement and vortex-split stratospheric sudden warmings: Influence of the Madden-Julian oscillation and quasi-biennial oscillation. J. Geophys. Res. Atmos., 119, 12 599-12 620, https://doi.org/10.1002/2014JD021876.

_ , Y. Liu, and Y.-L. Zhang, 2015: Simulation of the MaddenJulian oscillation in wintertime stratospheric ozone over the Tibetan Plateau and East Asia: Results from the Specified Dynamics version of the Whole Atmosphere Community Climate Model. Atmos. Ocean. Sci. Lett., 8, 264-270, https:// doi.org/10.3878/AOSL20150020.

Lu, H., T. J. Bracegirdle, T. Phillips, A. Bushell, and L. Gray, 2014: Mechanisms for the Holton-Tan relationship and its decadal variation. J. Geophys. Res. Atmos., 119, 2811-2830, https://doi.org/ 10.1002/2013JD021352.

Madden, R. A., and P. R. Julian, 1971: Detection of a 40-50 day oscillation in the zonal wind in the tropical Pacific. J. Atmos. Sci., 28, 702-708, https://doi.org/10.1175/1520-0469(1971)028<0702: DOADOI $>2.0 . \mathrm{CO} ; 2$.

—, and — 1972: Description of global-scale circulation cells in the tropics with a 40-50 day period. J. Atmos. Sci., 29, 1109-1123, https://doi.org/10.1175/1520-0469(1972)029<1109: DOGSCC $>2.0 . \mathrm{CO} ; 2$.

$\longrightarrow$, and - 1994: Observations of the 40-50-day tropical oscillation-A review. Mon. Wea. Rev., 122, 814-837, https://doi.org/ 10.1175/1520-0493(1994)122<0814:OOTDTO >2.0.CO;2.

Manzini, E., M. A. Giorgetta, M. Esch, L. Kornblueh, and E. Roeckner, 2006: The influence of sea surface temperatures on the northern winter stratosphere: Ensemble simulations with the MAECHAM5 model. J. Climate, 19, 3863-3881, https://doi.org/10.1175/JCLI3826.1.

Marsh, D. R., M. J. Mills, D. E. Kinnison, J.-F. Lamarque, N. Calvo, and L. M. Polvani, 2013: Climate change from 1850 to 2005 simulated in CESM1(WACCM). J. Climate, 26, 73727391, https://doi.org/10.1175/JCLI-D-12-00558.1.

Matsuno, T., 1966: Quasi-geostrophic motions in the equatorial area. J. Meteor. Soc. Japan, 44, 25-43, https://doi.org/10.2151/ jmsj1965.44.1_25.

Matthews, A. J., B. J. Hoskins, and M. Masutani, 2004: The global response to tropical heating in the Madden-Julian oscillation during the northern winter. Quart. J. Roy. Meteor. Soc., 130, 1991-2011, https://doi.org/10.1256/qj.02.123.

Mori, M., and M. Watanabe, 2008: The growth and triggering mechanism of the PNA: A MJO-PNA coherence. J. Meteor. Soc. Japan, 86, 213-236, https://doi.org/10.2151/jmsj.86.213.

Neale, R. B., J. Richter, S. Park, P. H. Lauritzen, S. J. Vavrus, P. J. Rasch, and M. H. Zhang, 2013: The mean climate of the Community Atmosphere Model (CAM4) in forced SST and fully coupled experiments. J. Climate, 26, 5150-5168, https:// doi.org/10.1175/JCLI-D-12-00236.1. 
Newman, M., and P. D. Sardeshmukh, 2008: Tropical and stratospheric influences on extratropical short-term climate variability. J. Climate, 21, 4326-4347, https://doi.org/10.1175/ 2008JCLI2118.1.

Newman, P. A., and E. R. Nash, 2000: Quantifying the wave driving of the stratosphere. J. Geophys. Res., 105, 12 485-12497, https://doi.org/10.1029/1999JD901191.

Perlwitz, J., and H.-F. Graf, 2001: Troposphere-stratosphere dynamic coupling under strong and weak polar vortex conditions. Geophys. Res. Lett., 28, 271-274, https://doi.org/10.1029/ 2000GL012405.

- , and N. Harnik, 2004: Downward coupling between the stratosphere and troposphere: The relative roles of wave and zonal mean processes. J. Climate, 17, 4902-4909, https://doi.org/ 10.1175/JCLI-3247.1.

Polvani, L. M., and D. W. Waugh, 2004: Upward wave activity flux as a precursor to extreme stratospheric events and subsequent anomalous surface weather regimes. J. Climate, 17, 3548-3554, https:// doi.org/10.1175/1520-0442(2004)017<3548:UWAFAA >2.0.CO;2.

Randel, W. J., F. Wu, and R. Stolarski, 2002: Changes in column ozone correlated with the stratospheric EP flux. J. Meteor. Soc. Japan, 80, 849-862, https://doi.org/10.2151/jmsj.80.849.

Ren, R.-C., M. Cai, C. Xiang, and G. Wu, 2012: Observational evidence of the delayed response of stratospheric polar vortex variability to ENSO SST anomalies. Climate Dyn., 38, 13451358, https://doi.org/10.1007/s00382-011-1137-7.

Schwartz, C., and C. I. Garfinkel, 2017: Relative roles of the MJO and stratospheric variability in North Atlantic and European winter climate. J. Geophys. Res. Atmos., 122, 4184-4201, https://doi.org/10.1002/2016JD025829.

Seo, K.-H., and S.-W. Son, 2012: The global atmospheric circulation response to tropical diabatic heating associated with the Madden-Julian oscillation during northern winter. J. Atmos. Sci., 69, 79-96, https://doi.org/10.1175/2011JAS3686.1.

Subramanian, A. C., M. Jochum, A. J. Miller, R. Murtugudde, R. Neale, R. B. Neale, and D. E. Waliser, 2011: The MaddenJulian oscillation in CCSM4. J. Climate, 24, 6261-6282, https:// doi.org/10.1175/JCLI-D-11-00031.1.

Sun, C., J. Li, and S. Zhao, 2015: Remote influence of Atlantic multidecadal variability on Siberian warm season precipitation. Sci. Rep., 5, 16853, https://doi.org/10.1038/ srep16853.

_,- R. Ding, and Z. Jin, 2017: Cold season Africa-Asia multidecadal teleconnection pattern and its relation to the Atlantic multidecadal variability. Climate Dyn., 48, 39033918, https://doi.org/10.1007/s00382-016-3309-y.

Thompson, D. W. J., and J. M. Wallace, 2001: Regional climate impacts of the Northern Hemisphere annular mode. Science, 293, 85-89, https://doi.org/10.1126/science.1058958.

Wheeler, M. C., and H. H. Hendon, 2004: An all-season realtime multivariate MJO index: Development of an index for monitoring and prediction. Mon. Wea. Rev., 132, 1917-1932, https://doi.org/10.1175/1520-0493(2004)132<1917: AARMMI $>2.0 . \mathrm{CO} ; 2$.

Wu, Z., X. Li, Y. Li, and Y. Li, 2016: Potential influence of Arctic sea ice to the interannual variations of East Asian spring precipitation. J. Climate, 29, 2797-2813, https://doi.org/10.1175/ JCLI-D-15-0128.1.

Xie, F., J. Li, W. Tian, J. Feng, and Y. Huo, 2012: Signals of El Niño Modoki in the tropical tropopause layer and stratosphere. Atmos. Chem. Phys., 12, 5259-5273, https://doi.org/10.5194/ acp-12-5259-2012.

- and Coauthors, 2016: A connection from Arctic stratospheric ozone to El Niño-Southern Oscillation. Environ. Res. Lett., 11, 124026, https://doi.org/10.1088/1748-9326/11/12/124026.

Xu, H., J. Li, J. Feng, and J. Mao, 2013: The asymmetric relationship between the winter NAO and the precipitation in southwest China. Acta Meteor. Sin., 70, 1276-1291.

Yang, C., T. Li, A. K. Smith, and X. Dou, 2017: The response of the Southern Hemisphere middle atmosphere to the Madden-Julian oscillation during austral winter using the Specified-Dynamics Whole Atmosphere Community Climate Model. J. Climate, 30, 8317-8333, https://doi.org/10.1175/ JCLI-D-17-0063.1.

Yoo, C., S. Feldstein, and S. Lee, 2011: The impact of the MaddenJulian oscillation trend on the Arctic amplification of surface air temperature during the 1979-2008 boreal winter. Geophys. Res. Lett., 38, L24804, https://doi.org/10.1029/2011GL049881. S. Lee, and S. B. Feldstein, 2012: Mechanisms of Arctic surface air temperature change in response to the MaddenJulian oscillation. J. Climate, 25, 5777-5790, https://doi.org/ 10.1175/JCLI-D-11-00566.1.

Zhang, C., M. Dong, S. Gualdi, H. H. Hendon, E. D. Maloney, A. Marshall, K. R. Sperber, and W. Wang, 2006: Simulations of the Madden-Julian oscillation in four pairs of coupled and uncoupled global models. Climate Dyn., 27, 573-592, https:// doi.org/10.1007/s00382-006-0148-2.

Zhang, J., W. Tian, F. Xie, Y. Li, F. Wang, J. Huang, and H. Tian, 2015a: Influence of the El Niño Southern Oscillation on the total ozone column and clear-sky ultraviolet radiation over China. Atmos. Environ., 120, 205-216, https://doi.org/10.1016/ j.atmosenv.2015.08.080.

, — - Z. Wang, F. Xie, and F. Wang, 2015b: The influence of ENSO on northern midlatitude ozone during the winter to spring transition. J. Climate, 28, 4774-4793, https://doi.org/ 10.1175/JCLI-D-14-00615.1.

,-- M. P. Chipperfield, F. Xie, and J. Huang, 2016: Persistent shift of the Arctic polar vortex towards the Eurasian continent in recent decades. Nat. Climate Change, 6, 10941099, https://doi.org/10.1038/nclimate3136.

Zhao, S., J. Li, and Y. Li, 2015: Dynamics of an interhemispheric teleconnection across the critical latitude through a southerly duct during boreal winter. J. Climate, 28, 7437-7456, https:// doi.org/10.1175/JCLI-D-14-00425.1.

Zheng, F., J. Li, Y. Li, S. Zhao, and D. Deng, 2016: Influence of the summer NAO on the spring-NAO-based predictability of the East Asian summer monsoon. J. Appl. Meteor. Climatol., 55, 1459-1476, https://doi.org/10.1175/JAMC-D-15-0199.1.

Zhou, S., and A. J. Miller, 2005: The interaction of the MaddenJulian oscillation and the Arctic Oscillation. J. Climate, 18, 143-159, https://doi.org/10.1175/JCLI3251.1. 